\title{
TESES E DISSERTAÇÕES SOBRE O ENVELHECIMENTO PRODUZIDAS NA UNIVERSIDADE FEDERAL DO RIO GRANDE DO SUL E INCLUÍDAS NO SISTEMA DE BIBLIOTECAS NO ANO DE 20071
}

CANEPPELE, Maria Cristina Garcia de Lima. Capacidade Funcional e Qualidade de Vida de Indivíduos Idosos de Porto Alegre. 2007. 190 f. Tese (Doutorado em Ciências Médicas) - Faculdade de Medicina, Universidade Federal do Rio Grande do Sul, Porto Alegre, 2007. Orientador: Profa. Dra. Sandra Cristina Pereira Costa Fuchs. Disponível em: $<$ http://www.bibliotecadigital.ufrgs.br/da.php?nrb=000645231\&loc $=2008 \& l=39 \mathrm{~d} 2 \mathrm{e} 6564 \mathrm{fd} 1 \mathrm{~d} 5 \mathrm{aa}>$.

\section{Resumo}

Fundamento: $\mathrm{O}$ crescimento da população idosa é um fenômeno mundial. $\mathrm{O}$ envelhecimento aumenta o risco para a ocorrência de doenças crônicas que resultam em graus variáveis de perda da independência funcional. A elevação da idade também pode acarretar a redução da independência funcional, tornando os idosos dependentes para a realização de atividades da vida diária (AVDs) e atividades instrumentais da vida diária (AIVDs). Objetivos: O objetivo desse estudo foi avaliar a capacidade funcional, determinando a prevalência de independência funcional e as características associadas em indivíduos idosos, em uma amostra representativa de Porto Alegre, RS, bem como identificar sua associação com qualidade de vida. Essa pesquisa é um dos braços do estudo da Síndrome de Obesidade e Fatores de Risco - SOFT. Participantes e Métodos: Nesse estudo transversal, de base populacional, de indivíduos idosos com 60 e 90 anos, selecionados através de amostragem por estágios múltiplos de conglomerados, em 106 dos 2157 setores censitários de Porto Alegre.

Em entrevistas domiciliares aplicou-se um questionário padronizado, para investigar características socioeconômicas, demográficas, hábitos de vida, fatores de risco para doença cardiovascular, além do índice de independência nas atividades de vida diária, desenvolvido por Katz, em1969, e a escala de independência nas atividades instrumentais da vida diária, criado

1 Levantamento realizado por Luís Fernando Pinheiro. Foram utilizados os seguintes descritores: Envelhecimento, Geriatria, Gerontologia, Idoso, Odontologia Geriátrica, Terceira Idade, Velhice.

Estud. interdiscip. envelhec., Porto Alegre, v. 13, n. 1, p. 147-163, 2008. 
por Lawton e Brody, em 1983, assim como o questionário de qualidade de vida Short Form-12 (Ware,1994). Utilizou-se o módulo Complex Samples, do SPSS, para as análises dos dados, a fim de ajustar para o efeito da amostragem. Testaram-se diferenças entre proporções utilizando-se o teste do quiquadrado de Pearson, ao analisarem-se as prevalências; análise de variância ou co-variância para compararem-se médias, e análise de regressão logística múltipla, para cálculo da odds ratio e intervalo de confiança de 95\%. As análises foram para um nível de significância de 5\%.

Resultados: A média de idade foi semelhante entre homens e mulheres idosos, e a distribuição de idade e sexo foi similar à do censo do Instituto Brasileiro de Geografia e Estatística. Além de maior escolaridade (8,8 vs. 6,6 anos), os homens referiram estar casados mais freqüentemente $(75,7 \%)$ do que as mulheres $(31,9 \%)$, as quais eram predominantemente viúvas ou separadas e residiam sozinhas em maior proporção. Com exceção de cor da pele e de residir sozinho, as demais características associaram-se significativamente com a idade. Identificou-se uma relação inversa entre idade e escolaridade e com o estar casado ou residir com companheiro, e uma associação direta com aposentadoria, separação ou viuvez e o uso de dispositivos para andar. Associação direta e independente de idade e sexo foi observada entre escolaridade e independência para realizar as atividades instrumentais, mas não para as atividades da vida diária. A prática de atividade física regular foi preditora de independência funcional nas AVDs e nas AIVDs. Esse estudo verificou tendência a maior independência entre os homens para o total de domínios das AVDs (94\% vs. 89\%; p=0,09), assim como das AIVDs (94\% vs. 88\%; $\mathrm{p}=0,04)$.

Nos homens, observou-se a redução da independência funcional para realizar a maior parte das AVDs e AIVDs com o avançar da idade. Entre as mulheres, destaca-se, a redução da independência funcional com a idade em todas as atividades, exceto usar o telefone. O sexo masculino esteve associado, independentemente da idade, a maiores escores dos componentes físico e mental da qualidade de vida. A idade associou-se inversamente com o componente físico, enquanto a escolaridade o fez de maneira direta. Entretanto, nenhuma dessas características mostrou relação com o componente mental. Ser ativo fisicamente e possuir menor número de condições crônicas se associaram tanto ao escore do componente físico quanto mental, de maneira fortemente significativa. Conclusão: Os indivíduos idosos investigados no Estudo SOFT, representam a população idosa de Porto Alegre. As diferenças entre homens e mulheres idosos incluem características socioeconômicas, 
hábitos de vida e independência funcional. Os homens apresentam maior qualidade de vida do que as mulheres, independentemente da idade.

Palavras-chave: Doença. Qualidade de vida. Idoso. Atividade motora. Atividades cotidianas. Epidemiologia. Porto Alegre.

CASTRO, Inês Alencar de. Expressão da Proteína p53 em Diferentes Níveis de Fotoenvelhecimento da Pele. 2007. 70 f. Dissertação (Mestrado em Ciências Médicas) - Faculdade de Medicina, Universidade Federal do Rio Grande do Sul, Porto Alegre, 2007. Orientador: Prof. Dr. Lúcio Bakos. Disponível em: $<$ http://www.bibliotecadigital.ufrgs.br/da.php?nrb=000622 $889 \& 10 c=2008 \& 1=a 514 e 49 b 8888 b 995>$.

\section{Resumo}

Este estudo se propõe a avaliar a expressão da proteína p53 em queratinócitos de antebraços de indivíduos com níveis diferentes de fotoenvelhecimento. $\mathrm{O}$ fotoenvelhecimento é um processo crônico definido por alterações fisiológicas, histológicas e clínicas, induzidas pela radiação ultravioleta. A radiação solar é considerada o mais importante carcinógeno em humanos, induzindo e promovendo alteração de DNA nos queratinócitos até a conversão maligna. A expressão do p53, gene supressor de tumores, seria o grande marcador genético da tendência à malignização induzida pela radiação ultravioleta. As mutações no gene p53 precedem o câncer de pele, mas não está determinado em que momento. A importância da avaliação desta proteína no fotoenvelhecimento, seria para avaliar um indicador de mutação no gene p53 precocemente às lesões malignas, e, portanto, melhor compreender e prevenir o câncer de pele não-melanoma. Sessenta pacientes com fototipo II e fotoenvelhecimento cutâneo foram avaliados segundo dois critérios: quanto à presença de ceratoses actínicas, grupo $\mathrm{A}$, e quanto à presença de atrofia cutânea associada à elastose ou ao intenso ressecamento, grupo B. Ambos os grupos, com 60 pacientes, foram divididos em dois níveis: leve e grave. Câncer de pele diagnosticado previamente foi critério de exclusão.

Os dois grupos, de forma independente, foram comparados quanto à expressão da proteína p53 através do método de imunoistoquímica. Biópsias foram realizadas em pele exposta ao sol de antebraço esquerdo, para avaliação histológica e pelo método de imunoistoquímica. O p53 estava expresso em todas as biópsias, sendo encontrada, no grupo A, mediana de $10,8(2,8-23,3)$ no nível leve, com 43 pacientes e mediana de $20(9,5-26,3)$ 
no nível grave, com 17 pacientes. No grupo B, mediana de $11.3(3,0-22,9)$ no nível leve, com 36 pacientes, e mediana de 18,8 (5,4 -26,7) no nível grave, com 24 pacientes. As diferenças entre os níveis leve e grave, segundo os dois critérios, não foram significativas estatisticamente. Nesta amostra, não se encontrou diferença estatística quanto à expressão da proteína p53 nos diferentes níveis de fotoenvelhecimento. Diversas hipóteses podem justificar o resultado, sendo possível que as alterações moleculares no fotoenvelhecimento sejam muito precoces aos cânceres de pele.

Palavras-chave: Doença. Envelhecimento da pele. Proteína supressora de tumor p53.

COUTO, Maria Clara Pinheiro de Paula. Fatores de Risco e de Proteção na Promoção de Resiliência no Envelhecimento. 2007. 144 f. Dissertação (Mestrado em Psicologia do Desenvolvimento) - Instituto de Psicologia, Universidade Federal do Rio Grande do Sul, Porto Alegre, 2007. Orientadora: Profa. Dra. Silvia Helena Koller. Co-Orientadora: Profa. Dra. Rosa Ferreira Novo. Disponível em: $<$ http://www.bibliotecadigital.ufrgs.br/da.php?nrb=0 $00606274 \&$ loc $=2007 \& 1=\mathrm{e} 7087 \mathrm{ele} 2 \mathrm{fd} 951 \mathrm{e} 0>$.

\section{Resumo}

O objetivo deste estudo foi investigar como as variáveis rede de apoio social e resiliência articulam-se para a manutenção do bem-estar psicológico em idosos expostos a situações de ageismo e a eventos de vida estressantes. Visou-se, assim, identificar indicadores de risco e de proteção que influenciam o processo de desenvolvimento humano. Sob a perspectiva do risco, foram investigados o ageismo e os eventos de vida estressantes, e, sob a perspectiva da proteção, a resiliência, a rede de apoio social e o bem-estar psicológico. Participaram deste estudo, 111 idosos entrevistados individualmente ou em grupos de até dez. Os instrumentos utilizados foram um questionário de dados biosociodemográficos, a Ageism Survey, o Inventário de Eventos Estressantes entre Idosos, a Escala de Resiliência, as Escalas de Bem-Estar Psicológico (versão reduzida) e o Diagrama da Escolta. Para a analisar os dados, foram feitas análises de estatística descritiva, testes de comparação de médias (teste $t$ de Student e ANOVA one-way), testes de correlação de Pearson e regressões para análise de mediações com a resiliência como mediador entre eventos estressores e BEP, e ageismo e BEP. 
Os resultados indicaram que os eventos de vida estressantes podem ser considerados como fator de risco ao envelhecimento bem sucedido. Por sua vez, a rede de apoio social desempenha um papel de proteção capaz de promover o bem-estar e a resiliência em idosos. A resiliência opera como mediadora entre os eventos de vida estressantes e o bem-estar psicológico, ou seja, quando presente, é capaz de minorar os efeitos negativos do risco no bem-estar psicológico de idosos. Relativamente ao ageismo, o mesmo não pôde ser considerado como um fator de risco segundo os dados deste estudo. Mais pesquisas são necessárias para investigar o potencial papel de risco desta variável na velhice.

Palavras-chave: Psicologia do desenvolvimento. Fatores de risco. Idoso. Bem-estar. Discriminação. Resiliência (Psicologia). Redes de apoio social.

DE MARCHI, Renato José. Perda Dentária, Uso de Próteses e sua Associação com Estado Nutricional de Idosos Independentes de Carlos Barbosa, RS. 2007. 96 f. Dissertação (Mestrado em Odontologia) - Faculdade de Odontologia, Universidade Federal do Rio Grande do Sul, Porto Alegre, 2007. Orientadora: Profa. Dra. Dalva Maria Pereira Padilha. Disponível em: $<$ http://www.bibliotecadigital.ufrgs.br/da.php?nrb=000605498\&loc=2 $007 \& \mathrm{l}=4 \mathrm{e} 607 \mathrm{c} 56 \mathrm{~d} 7 \mathrm{ff} 3 \mathrm{af0}>$.

\section{Resumo}

O envelhecimento populacional é um processo que atingiu uma crescente velocidade nos países em desenvolvimento, entre eles, o Brasil. Saúde Bucal (SB) e Saúde Geral não podem ser vistas separadamente, e os impactos de uma SB comprometida são mais evidentes em idosos, os quais acumulam ao longo da vida as conseqüências de doenças bucais, freqüentemente refletidas em extensas perdas dentárias, xerostomia, uso de próteses e comprometimentos da mastigação. A associação entre o estado bucal e o estado nutricional de idosos tem recebido crescente atenção da comunidade científica, e diferentes autores têm indicado que perdas dentárias e o comprometimento da mastigação estão relacionados com a seleção de alimentos mais fáceis para mastigar, refletindo em prejuízos na nutrição destes indivíduos. Estudos realizados em diferentes amostras de idosos têm demonstrado uma relação entre perdas dentárias e outras variáveis de SB com o risco nutricional, bem como apontam para uma relação entre estado bucal precário e fragilidade entre idosos institucionalizados. O objetivo deste 
estudo foi verificar a associação entre o estado bucal e o estado nutricional de idosos independentes de Carlos Barbosa, RS. Quatrocentos e setenta e um indivíduos com 60 anos ou mais de idade, participaram da pesquisa. Foi aplicado um questionário incluindo o histórico de saúde geral e bucal, e variáveis sócio-demográficas.

Foi realizado um exame bucal onde foi levantado o número de dentes, uso de prótese e o estado das mucosas. A coleta de dados foi realizada de Março a Dezembro de 2006, com o apoio da Prefeitura Municipal de Carlos Barbosa. Os resultados deste estudo demonstram uma associação entre o estado bucal e o estado nutricional através da Mini- Avaliação Nutricional. Idosos edêntulos sem o uso de prótese total inferior e aqueles que reportaram sua saúde gengival como insatisfatória, estiveram em risco de desnutrição/ desnutrição $(\mathrm{p}<0,05)$. Estes resultados permitem concluir que o estado nutricional de idosos independentes pode estar relacionado com sua saúde bucal, e que em consonância com o que sugere a literatura, idosos edêntulos sem o uso de próteses podem estar em risco aumentado para desnutrição.

Palavras-chave: Odontologia. Odontologia geriátrica. Prótese dentária. Nutrição.

GOMES, Ângela. Envelhecer Saudável no Mundo do Trabalho: uma análise da intenção dos educandos no módulo "saúde e cidadania" do Programa Integrar. 2007. 249 f. Dissertação (Mestrado em Educação) - Escola de Educação, Universidade Federal do Rio Grande do Sul, Porto Alegre, 2007. Orientador: Prof. Dr. Johannes Doll. Disponível em: $<$ http://www.bibliotecadigital.ufrgs.br/da.php?nrb $=000623374 \&$ loc $=2008 \& 1=17121 \mathrm{b3a64ab4}$ $4 \mathrm{~b} 2>$.

\section{Resumo}

Este estudo analisa a proposta de inclusão do tema "Processo de envelhecimento no currículo do Programa Integrar", dentro do módulo "Saúde e Cidadania", bem como, um acompanhamento crítico-reflexivo dessa mudança curricular. Promove a reflexão sobre saúde e processo de envelhecimento para os educandos e propõe, a partir desta experiência, a inclusão desta temática no currículo do Programa Integrar de forma permanente para todos os seus núcleos. Assim como, propor a inclusão da temática também no currículo do PROEJA (Programa Nacional de Integração da Educação profissional 
à Educação Básica). Esta pesquisa desenvolveu-se em um dos núcleos do Programa Integrar/RS, com uma turma do Ensino Fundamental, formada por trinta e quatro educandos. O período de realização deste módulo totalizou 200 horas de atividades referentes às áreas de conhecimento e práticas de informática. Esta pesquisa, cuja abordagem é qualitativa, utiliza alguns elementos da pesquisa-ação. Realizou-se trinta e três entrevistas individuais semi-estruturadas, questionários com todos os educandos, observações em sala de aula e material produzido pelos mesmos. Inicialmente a coleta de dados teve como objetivo conhecer qual o entendimento que os educandos tinham sobre saúde, doença e envelhecimento; o que eles gostariam de saber sobre este tema, que tipo de trabalho realizam e se este causa algum problema de saúde. A partir desta coleta foram traçados temas de interesse dos alunos que foram trabalhados nesse módulo. Para a análise dos dados, priorizou-se uma abordagem qualitativa com base em categorias e interpretações para dar conta da "realidade" estudada.

As análises das categorias apontam que a maioria dos educandos voltou a estudar para se manter ou conseguir um trabalho e definiu saúde como "poder trabalhar" com o sentido de estar empregado e doença como aquela que impede as pessoas de trabalharem. Em relação à velhice, expressaram o medo de ficar velhos e doentes; o medo da dependência, abandono e solidão; e alguns relataram que é importante se preparar para a velhice. Paralelamente a temática do envelhecimento se discutiu/refletiu sobre saúde e cidadania buscando a conscientização de que para que haja mudança deve haver esforço, participação e responsabilidade de todos na luta por seus direitos. Evidenciou-se que, inicialmente, os educandos tinham resistência em falar e estudar sobre saúde e envelhecimento, mas à medida que foi compartilhada as histórias de vidas e materiais que abordaram estes temas, se perceberam sujeitos coletivos na busca por melhores condições de trabalho, educação, saúde, moradia e um envelhecimento digno. Este estudo é relevante porque buscou não prescrever regras de comportamento e sim, gerar oportunidades para que os educandos pudessem estar refletindo/ discutindo novas formas de pensar valores, crenças e expectativas sociais e individuais referentes ao processo de envelhecimento, de forma a oportunizar escolhas conscientes de qualidade de vida e a redução de preconceitos e estereótipos em relação à velhice.

Palavras-chave: Educação. Envelhecimento. Sujeito. Educação: saúde: Trabalho: interação. 
GUEWEHR, Katrine. Teoria da Resposta ao Item na Avaliação de Qualidade de Vida de Idosos. 2007. 180 f. Dissertação (Mestrado em Ciências Médicas) - Faculdade de Medicina, Universidade Federal do Rio Grande do Sul, Porto Alegre, 2007. Orientador: Prof. Dr. João Riboldi. Disponível em: $<$ http://www.bibliotecadigital.ufrgs.br/da.php?nrb=000628234\&loc $=2$ $008 \& 1=8066449997 \mathrm{dcec} 51>$.

\section{Resumo}

INTRODUÇÃO: A importância da avaliação da qualidade de vida no contexto da saúde vem ganhando crescente valorização tanto no meio acadêmico, quanto na sociedade, e esse fenômeno vem sendo amplamente reconhecido nas últimas décadas. Os idosos não fogem a esse panorama e almejam envelhecer com qualidade de vida. A Teoria Clássica dos Testes (TCT) foi, e ainda é, muito utilizada, mas apresenta várias limitações, e os modelos de Teoria da Resposta ao Item (TRI) lidam com consistência e eficiência na avaliação de tais desfechos, utilizando mais intensamente a informação presente nos instrumentos.

OBJETIVOS: Estruturar a TRI e aplicá-la aos resultados obtidos no uso de três instrumentos de avaliação de qualidade de vida, e comparar estes resultados com os resultados provenientes dos métodos tradicionais de análises, via TCT e Análise Fatorial. Comparar a equivalência do WHOQOL-BREVE e WHOQOL-100.

MÉTODO: Foi utilizado o Modelo Logístico de 2 Parâmetros na estimação da qualidade de vida global e por domínios a partir dos resultados obtidos com os instrumentos de avaliação de qualidade de vida elaborados pela OMS (WHOQOL-100 e WHOQOL-BREVE) e pela Escala de Qualidade de Vida de Flanagan (EQVF) em 400 idosos socialmente ativos da região metropolitana de Porto Alegre, Rio Grande do Sul. As respostas foram dicotomizadas após a realização da pesquisa. Foram verificadas as consistências internas de cada escala através do coeficiente $\alpha$ de Cronbach, e realizadas análises clássicas para cada instrumento, análises fatoriais, análises de variância com os escores brutos e os escores latentes obtidos na TRI, análises de correlação linear de Pearson entre os escores e a verificação da concordância através do coeficiente Kappa a partir da classificação com base na mediana dos escores.

RESULTADOS: As três escalas apresentaram valores altos de fidedignidade. Com base na aplicação do modelo de TRI na EQVF, verificouse que os idosos têm maior dificuldade de sentirem-se satisfeitos com sua 
aprendizagem, e que indivíduos com um bom nível de autoconhecimento, trabalho, boa comunicação e oportunidades de lazer tendem a ter um nível superior de qualidade de vida. Os escores brutos e latentes apresentaram uma correlação de 0,972 . Os fatores significantes na análise de variância para os escores brutos foram saúde percebida, níveis de depressão e desesperança. E com os escores latentes, apenas saúde percebida e depressão foram significantes a 1 e $5 \%$. Na EQVF, os idosos apresentaram concordância de classificação da qualidade de vida, e o item relativo à vida íntima foi retirado das análises devido à inconsistência. Através do WHOQOLBREVE, verificou-se que estes idosos têm maior dificuldade de estarem satisfeitos com sua qualidade de vida em geral, e dão grande importância para capacidade de desempenhar as atividades cotidianas. Os itens referentes à vida sexual, dinheiro suficiente para satisfazer suas necessidades e satisfação com o acesso aos serviços de saúde não se mostraram válidos para estimar a qualidade de vida de idosos na TRI, sendo retirados da estimação das habilidades. Os fatores influentes nos escores brutos e latentes são os mesmos: saúde percebida, níveis de depressão e desesperança, para o WHOQOL-BREVE e WHOQOL-100. As correlações entre os escores brutos e latentes para o WHOQOL-BREVE e WHOQOL-100 são 0,968 e 0,940, respectivamente. Foi encontrada concordância na classificação dos escores de qualidade de vida para o WHOQOL-100 e WHOQOL-BREVE. Com base na TRI foram encontrados baixos níveis de satisfação com a memória, vida sexual e situação financeira no WHOQOL- 100. O instrumento apresentou 35 itens inconsistentes.

CONCLUSÕES: Os resultados via TRI não diferem significativamente dos resultados dos métodos tradicionais, mas confirmam a TRI como um método promissor para avaliação de qualidade de vida.

Palavras-chave: Doença. Qualidade de vida. Idoso. Epidemiologia. Análise fatorial.

LICHTENFELS, Patricia. As Relações Sociais e as Funções das Mulheres Idosas da Vila Fátima na Constelação Familiar Atual. 2007. 105 f. Dissertação (Mestrado em Educação) - Faculdade de Educação, Universidade Federal do Rio Grande do Sul, Porto Alegre, 2007. Orientador: Prof. Dr. Johannes Doll. Disponível em: $<$ http://www.bibliotecadigital.ufrgs.br/da.p $\mathrm{hp} ? \mathrm{nrb}=000614898 \&$ loc $=2008 \& \mathrm{l}=9 \mathrm{a} 726 \mathrm{ac} 00 \mathrm{bedc} 71 \mathrm{f}>$. 


\section{Resumo}

Entre as preocupações e os estudos sobre o processo de envelhecimento, existe uma área que tem recebido grande atenção: a "feminização da velhice". As mulheres possuem uma maior expectativa de vida, com isso, as projeções para o futuro apontam para um crescimento da população idosa feminina e um relativo decréscimo da masculina. Esses índices não apenas destacam uma superioridade numérica das mulheres na velhice, mas nos fazem refletir sobre as necessidades de conhecer e contemplar esse maior segmento da população idosa nacional. O presente estudo foi desenvolvido num contexto de famílias urbanas de um bairro de classe popular da cidade de Porto Alegre, a Vila Fátima, e teve como objetivo principal analisar as funções que as mulheres idosas deste bairro estão desempenhando hoje em suas famílias. Os objetivos secundários foram: o levantamento do perfil socioeconômico das famílias deste bairro; a análise da estrutura familiar e da rede social de apoio das famílias; e a compreensão da percepção que a mulher idosa tem de si mesma dentro de sua família e na comunidade onde vive.

Participaram do estudo nove mulheres, com idades entre 66 e 93 anos, moradoras da Vila Fátima, integrantes do Grupo de Terceira Idade do Centro de Extensão Universitária da PUC-RS. Nesta pesquisa, de cunho qualitativo e caráter etnográfico, utilizaram-se como instrumentos de coleta de dados: entrevistas com perguntas abertas, gravadas e posteriormente transcritas, que foram realizadas no próprio domicílio das participantes; um diário de campo e anotações sobre o Grupo de Terceira Idade. O estudo mostrou que o processo de adoecimento crônico, a prisão ou a perda precoce do companheiro, seja por morte ou por separação, levou sete entre as nove entrevistadas a constituir unidades-mãe-filhos e a assumir o papel de provedoras de seus lares. Os vizinhos, as creches locais e o posto de saúde formam a rede social de apoio na comunidade. Com o envelhecimento, algumas delas continuaram a viver na forma de unidade-mãe-filhos, e outras passaram a constituir unidade-mãe-filhos-netos. Elas continuaram a desempenhar um papel central no funcionamento de suas famílias e sustento de suas casas.

Muitas das idosas assumiram a responsabilidade de criar e educar seus netos e bisnetos. A sua principal fonte de suporte social hoje são seus filhos. A co-residência é uma realidade muito presente nesse contexto. Ela tem gerado um aumento da taxa de escolarização, uma redução do trabalho infantil e proporcionando trocas intensas e prolongadas entre as gerações. As trocas de carinho, o diálogo aberto com os netos e a disponibilidade de 
estar presente e ser uma referência são características marcantes nos discursos das idosas. A relação afetiva firmada com as gerações mais jovens possibilita aos idosos uma releitura crítica de suas trajetórias pessoais e a construção de um novo sentido de vida.

Palavras-chave: Educação. Mulher idosa: educação. Mulher idosa: família. Relações familiares: gênero. Envelhecimento.

RINALDI, Juciclara. Influência do Hipertexto na Compreensão Textual de Pacientes com Demência de Alzheimer Leve e Moderada. 2007. 92 f. Dissertação (Mestrado em Psicologia do Desenvolvimento) - Instituto de Psicologia, Universidade Federal do Rio Grande do Sul, Porto Alegre, 2007. Orientadora: Profa. Dra. Maria Alice de Mattos Pimenta Parente. Disponível em: $<$ http://www.bibliotecadigital.ufrgs.br/da.php?nrb=000595278\&loc $=20$ $07 \& \mathrm{l}=7 \mathrm{c} 18 \mathrm{ebe} 4 \mathrm{f} 6 \mathrm{da} 34 \mathrm{ec}>$.

\section{Resumo}

A leitura em hipertexto foi difundida por meio da tecnologia da informação, sendo importante identificar em quais áreas esta tecnologia melhora a compreensão textual, quando comparada ao texto linear. Com o objetivo de verificar se o hipertexto facilita o reconto de idosos com Demência de Alzheimer, analisou-se 40 idosos: 25 com DAs prováveis, sendo 12 leves e 13 moderados; e 15 sem demência, com idades entre 60 e 84 anos e escolaridade acima de 4 anos. A compreensão textual mostrou ser uma tarefa sensível aos participantes com demência, cujo desempenho foi significativamente pior do que o dos idosos normais. A história em hipertexto auxiliou os participantes com DA leve. Os grupos de DA leve e moderada lembraram da idéia principal da história, contudo somente o grupo de demência inicial lembrou de detalhes. Verificou-se que quanto mais grave a demência maior o número de acréscimos ao enredo e menor o percentual de proposições lembradas. Os resultados sugerem que, devido à dificuldade das memórias de trabalho e episódica, os participantes recorreram a recursos, ainda presentes, da memória semântica para completar a história.

Palavras-chave: Psicologia cognitiva. Psicologia do desenvolvimento. Doença de Alzheimer. Compreensão da leitura. Hipertexto. Idoso. Linguagem. Cognição. 
SCHMIDT, Cristiane. As Relações entre Avós e Netos: possibilidades coeducativas? 2007. 137 f. Dissertação (Mestrado em Educação) - Escola de Educação, Universidade Federal do Rio Grande do Sul, Porto Alegre, 2007. Orientador: Prof. Dr. Johannes Doll. Disponível em: $<$ http://www.bibliotecadigital.ufrgs.br/da.php?nrb=000617681\&loc=2008\&l=3ee6894d5f5ea81a $>$.

\section{Resumo}

A presente dissertação visa compreender como se constitui a relação entre adolescentes, na condição de netos e seus respectivos avós no âmbito familiar. As pessoas idosas constituem hoje um segmento da sociedade que vem adquirindo mais visibilidade em função da maior longevidade. Ao mesmo tempo, as formas de ser e estar em família na contemporaneidade vem apresentando constantes modificações. Nesse sentido, evidencia-se na atualidade uma pluralidade de configurações familiares, como as famílias de idosos e as famílias com idosos. Outra característica marcante dessa diversidade é a família longeva traduzindo-se como um fenômeno novo e apresentando a coexistência de várias gerações. Dentro desse cenário procura-se entender como se constituem a identidade e como se relacionam dois grupos etários: a adolescência e a velhice. As teorias específicas sobre a constituição da identidade geracional trazem contribuições importantes para a compreensão da relação intergeracional. Considerando o convívio entre avós e netos como benéfico, estuda-se quais são as transmissões de um geração a outra e de que modo ocorrem tais contribuições.

Desta maneira, a presente pesquisa analisa o contato entre gerações enquanto uma possibilidade de co-educação através de um estudo qualitativo. Esse trabalho foi realizado junto a alunos adolescentes de uma escola pública do município de São Leopoldo e junto aos seus avós, residentes na mesma localidade. A coleta de dados sucedeu-se através de um questionário e do registro de diários dos jovens, bem como por intermédio de entrevistas dos idosos acerca de sua relação com o outro. Trata-se de oito jovens com idades entre 15 e 18 anos e de 12 idosos dos 62 aos 78 anos. Os dados foram analisados através da construção de categorias analíticas sob o enfoque do método hermenêutico ou interpretativo. A partir dos resultados ficou assinalado que o convívio intergeracional mediado pelas relações familiares possibilita uma co-educação, visto que existe uma troca de conhecimentos, de afetividade, de valores, de cuidados, evidenciando a reciprocidade entre as gerações. Ao mesmo tempo, essa relação não desconsidera a influência 
dos discursos acerca das identidades geracionais, discursos esses, geralmente marcados por estereótipos.

Palavras-chave: Educação. Relações familiares: Avós. Relações intergeracionais. Idoso. Relações familiares: netos.

SCHOSSLER, Thaís. Cuidador Domiciliar do Idoso: cuidando de si e sendo cuidado pela equipe de saúde: uma análise através da Teoria do Cuidado Humano de Jean Watson. 2007. 102 f. Dissertação (Mestrado em Enfermagem) - Escola de Enfermagem, Universidade Federal do Rio Grande do Sul, Porto Alegre, 2007. Orientadora: Profa. Dra. Maria da Graça Oliveira Crossetti. Disponível em: $<$ http://www.bibliotecadigital.ufrgs.br/da.php?nr $b=000603489 \& l o c=2007 \& 1=8 b 2 d d 117200 f f f b f>$.

\section{Resumo}

Este estudo teve como objetivo conhecer a percepção do cuidador domiciliar do idoso sobre o cuidado de si e o cuidado que a equipe de saúde lhe proporciona, tendo como base teórica o referencial de Jean Watson em sua Teoria do Cuidado Humano. A pesquisa caracterizou-se por uma abordagem qualitativa, do tipo exploratório descritiva. O estudo foi desenvolvido na Unidade da Vila Floresta que faz parte do Serviço de Saúde Comunitária do Grupo Hospitalar Conceição. Participaram do estudo nove cuidadores domiciliares de idosos integrantes do Programa de Assistência Domiciliar, da unidade campo deste estudo. A coleta de informações se deu através de entrevista semi-estruturada (TRIVIÑOS, 1987), realizada no domicílio dos participantes ou na Unidade de Saúde. Para análise das informações foi utilizada a análise de conteúdo proposta por Bardin (1977). Os aspectos éticos foram atendidos de acordo com as Diretrizes e Normas Regulamentadoras da resolução 196/96.

Da análise das entrevistas emergiram as seguintes categorias: consciência intencional: olhares necessários para cuidar de si; compromisso moral com a consciência de cuidado do outro resultando no (des)cuidado de si; consciência, sensibilidade e espiritualidade: transcender no encontro de cuidado para melhor cuidar de si; a equipe de saúde e o cuidador domiciliar: a necessidade do cuidado transpessoal. Conclui-se que o cuidador domiciliar é o principal responsável pelo cuidado ao idoso, mas conta com apoio de familiares e vizinhos em alguns momentos. O cuidado de si se faz presente em certos momentos na realidade dos participantes do estudo e, 
em outros, alguns fatores impedem a sua realização. O cuidador domiciliar reconhece a presença da espiritualidade na relação de cuidado para consigo e do idoso. Quanto ao atendimento que recebem da equipe de saúde, os participantes do estudo expressam que sentem-se acolhidos e cuidados, e em outros momentos encontram dificuldades em relação ao acesso à equipe de saúde e à falta da sua presença no domicílio.

Palavras-chave: Enfermagem. Cuidados domiciliares de saúde. Enfermagem geriátrica. Enfermagem domiciliar. Cuidadores: idoso. Teoria de enfermagem. Serviços de assistência domiciliar. Jean Watson.

SOUZA, Luccas Melo de. Trabalho Voluntário, Saúde e Qualidade de Vida em Idosos. 2007. 123 f. Dissertação (Mestrado em Enfermagem) - Escola de Enfermagem, Universidade Federal do Rio Grande do Sul, Porto Alegre, 2007. Orientadora: Profa. Dra. Liana Lautert. Disponível em: $<$ http://www. bibliotecadigital.ufrgs.br/da.php?nrb $=000596838 \&$ loc $=2007 \& 1=0$ ce 24374 1320ce34>.

\section{Resumo}

Trata-se de um estudo transversal, comparativo, do tipo ex post facto, contemplando uma pesquisa de abordagem quantitativa que objetivou: descrever as características socioeconômicas e demográficas e as condições de saúde autopercebidas de idosos que realizavam trabalho voluntário; avaliar a qualidade de vida desses idosos e de idosos que não realizavam trabalho voluntário; correlacionar a autopercepção da saúde e os escores de depressão e de qualidade de vida de um grupo de idosos com o desenvolvimento de trabalho voluntário. Foram entrevistados 207 idosos divididos em dois grupos pareados: 174 idosos que realizavam trabalho voluntário vinculados a uma Organização Não-Governamental da cidade de Porto Alegre e 33 idosos que não realizavam voluntariado. Os dados demonstram que $87,4 \%$ dos idosos voluntários entrevistados eram do sexo feminino, na faixa etária de 60 a 69 anos, com, em média, 11,5 anos de escolaridade e renda própria, em sua maioria, religiosos e adeptos a práticas de saúde. Quando comparados os dados dos grupos de idosos voluntários e não-voluntários, a autopercepção da saúde como ótima foi maior nos voluntários $(30,5 \%$ versus $06,1 \%)$ enquanto a prevalência de depressão foi menor $(01,2 \%$ versus 09,1\%), com $\mathrm{P}=0,05$. 
Não houve diferença estatisticamente significativa entre os grupos nos escores dos domínios físico e meio ambiente da escala de qualidade de vida do Whoqol-bref, o que foi atribuído à técnica de pareamento utilizada nos grupos. Nos domínios psicológicos, relações sociais e na avaliação global, os idosos voluntários apresentaram escores mais elevados, quando comparados com os não voluntários, com significância estatística $(\mathrm{P} \leq 0,05)$, talvez relacionada com os benefícios advindos com a realização do voluntariado, tais como alegria, felicidade, amizade, qualidade de vida e saúde, entre outros. No modelo de regressão linear, o fato de ser voluntário mostrou-se influenciador para maiores escores no domínio psicológico, na avaliação global e na autopercepção ótima da saúde. Os resultados da investigação fornecem subsídios para a hipótese de que o trabalho voluntário atue como um mecanismo de promoção da saúde e da qualidade de vida desses idosos voluntários.

Palavras-chave: Enfermagem. Saúde do idoso. Trabalho voluntário: idoso. Qualidade de vida: idoso. Depressão.

STEFFEN, Marisa Fontoura. Literatura Infanto-Juvenil: possibilidade de construção de novos saberes sobre o processo de envelhecimento. 2007. 188 f. Dissertação (Mestrado em Educação) - Escola de Educação, Universidade Federal do Rio Grande do Sul, Porto Alegre, 2007. Orientador: Prof. Dr. Johannes Doll.

\section{Resumo}

Esta dissertação de Mestrado parte do desejo de estudar e conhecer, através da literatura infanto-juvenil, que imagens de velho as obras Receita para um Dragão, de Simone Saueressig, O Outro Lado do Tabuleiro, de Eliane Ganem e Vovô Fugiu de Casa, de Sérgio Caparelli apresentam. Mostra ainda, a importância da literatura como possibilidade de construção de novos saberes a respeito do processo de envelhecimento, e discute a necessidade de a escola, através de seu currículo, inserir conteúdos voltados para o processo de envelhecimento, a fim de despertá-la como espaço de promoção do ser que envelhece. Para a realização da pesquisa, de natureza qualitativa, selecionamos autores da área da gerontologia, para verificarmos que conceitos de velhice apresentam, que apontamentos fazem a respeito dos processos diferenciais do envelhecimento, que discussão os autores apresentam a respeito das imagens da velhice e do envelhecimento que 
a mídia veicula, qual a postura dos estudiosos frente ao entendimento do processo de envelhecimento como um processo de perdas e aquisições, o que discutem os estudiosos sobre os estereótipos carregados pelos seres que envelhecem e, por fim, qual a postura desses pesquisadores do processo de envelhecimento frente à idéia de que a velhice ainda é um fenômeno a ser desvendado. $\mathrm{O}$ diálogo dos pesquisadores da área da gerontologia com as obras literárias, a interpretação e a análise da pesquisadora dos textos literários e da bibliografia recolhida para estudo e a compilação dos mais diversos saberes a respeito do processo de envelhecimento, possibilitounos concluir que as obras analisadas apresentam imagens mais positivas da velhice.

Palavras-chave: Educação. Envelhecimento. Velhice. Literatura infantojuvenil. Pessoa idosa.

WAGNER, Gabriela Peretti. Disfunções Executivas no Envelhecimento Cognitivo: investigações com os instrumentos Tarefa do Jogo e Teste Wisconsin de Classificação de Cartas. 2006. 121 f. Dissertação (Mestrado em Psicologia do Desenvolvimento) - Instituto de Psicologia, Universidade Federal do Rio Grande do Sul, Porto Alegre, 2006. Orientadora: Profa. Dra. Maria Alice de Mattos Pimenta Parente. Disponível em: $<$ http://www.bibliotecadigital. ufrgs.br/da.php?nrb=000610819\&loc $=2007 \& 1=0$ be9fee5f9610773 $>$.

\section{Resumo}

Esta dissertação consiste em dois estudos que têm por objetivo investigar a existência de disfunções executivas no envelhecimento. Estudos recentes sugerem a existência de disfunções executivas no Declínio Cognitivo Leve (DCL). O objetivo do Estudo 1 foi verificar a presença de disfunções executivas em pacientes com DCL. Os instrumentos utilizados foram o Teste Wisconsin de Classificação de Cartas (WCST) e a Iowa Gambling Test (IGT). Foram estudados dez pacientes com e 27 sem DCL. Os dados foram analisados através do teste $t$ de Student para amostras independentes e da análise de variância (ANOVA) para medidas repetidas. Os resultados não evidenciaram diferença significativa entre os grupos nos índices de resposta do WCST e no número de cartas retiradas de cada baralho no IGT. O estudo da evolução do desempenho no IGT revelou diferença qualitativa entre os grupos. Idosos sem DCL aprendem ao longo da tarefa, enquanto idosos com DCL não o fazem, sugerindo uma interferência dos sistemas 
de memória na tomada de decisão. O Iowa Gambling Test tem sido um instrumento utilizado na avaliação da tomada de decisão.

O objetivo do Estudo 2 foi investigar se alterações nos procedimentos de aplicação do instrumento interferem no desempenho durante a execução do teste. Foi realizado um estudo transversal comparando dois grupos de idosos saudáveis em duas variações do instrumento. O grupo I contou com 27 participantes, que executaram a tarefa sem pista de reforço visual. $\mathrm{O}$ grupo II foi composto por 17 participantes, submetidos à tarefa com pista. Os dados foram analisados através dos testes $t$ de Student para amostras independentes e ANOVA para medidas repetidas. Houve diferença estatisticamente significativa entre os dois grupos na execução do teste em relação à aversão ao risco $(\mathrm{F}=2,466 ; \mathrm{p}=0,05 ; \mathrm{df}=2)$. Os resultados indicam que uma pista de reforço visual possibilita maior alocação de recursos atencionais e de memória de trabalho, permitindo que os idosos tomem decisões menos arriscadas.

Palavras-chave: Psicologia cognitiva. Psicologia do desenvolvimento. Envelhecimento. Processos cognitivos. Cognição. 